Basrah Journal

of Surgery
Editorial

Bas J Surg, June, 24, 2018

\title{
LESSONS TO BE LEARNED \\ LESSONS TO BE AVOIDED IN THE FUTURE
}

\section{Thamer A Hamdan}

MB,ChB, FRCS, FICS, FACS, Professor of Orthopedic Surgery, Chancellor of Basrah University, Basrah, IRAQ.

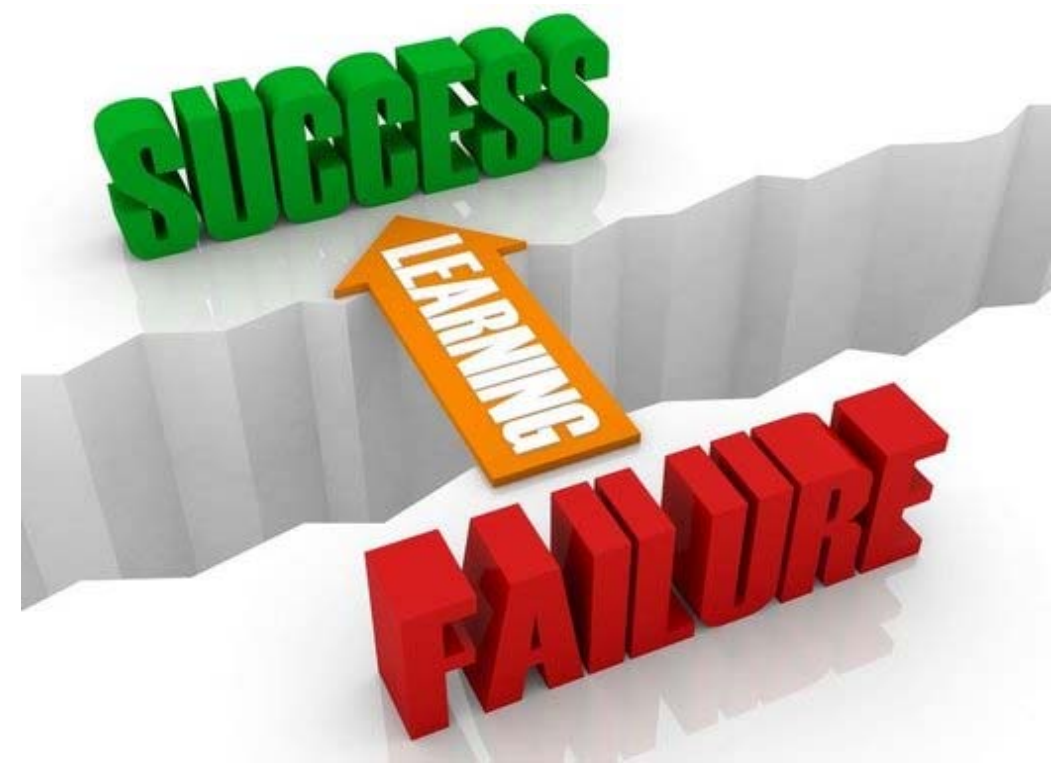

T is a well-known fact that lucky is the one whose mistakes can be counted. There is Inot a single surgeon who has not had complications of one type or another. Those who deny complications either have not done enough surgery or not telling the truth.

Surgeons may have complications in spite of good judgment and proper execution of surgical procedures. Simply speaking, complications should be the pillars for future rectification of personal and colleague's careers. It is a shame when surgeons discover at time of surgery, that something was missed prior to putting the knife on the patient's body. Certainly, this situation is embarrassing or even perplexing for the surgeon, because he may feel, he do not know how to behave when he faces a surprise. It is really painful when he feels he is guilty by the sin of omission or commission.

At the same time, we should admit that we have faced some unexpected findings at the time of surgery. However, we may not be blamed because this was not due to lack of proper pre-operative evaluation but because of similarities of clinical manifestations or due to masking of the cardinal clinical features. One of the best example is emergency operation for acute appendicitis, while the operative findings are suggestive of ovarian cyst.

The good surgeon should have the capability of behaving accordingly, when the operative field dictates what to do. I have seen surgeons collapsing and losing their way when they faced the unexpected. Of course, this is a tear in their practice because they should be ready to behave rationally even with the unexpected situations. 
Needless to say, the human body is one block; limbs are attached to the body and so is the situation with kidneys and stomach. This does indicate that multiple pathology somewhere else in the body could lie behind poor outcome, particularly when the second or third pathology is missed while it is the real symptom generator, and the knife was applied to other parts the body. This suggests that to avoid such painful situation, we have to be thorough in our thinking and our behavior, so that we do not fall in the trap. I came across such situations in my career several times, which was really shocking. Some of these situations are related to radiology findings when the fracture was not comminuted on X-ray but very comminuted in the operative field, which necessitates a change in the plan instantly. Hopefully, the prepared instruments and fixators can cope with this situation.

Another status is a pathological fracture discovered at the time of surgery because of lack of thorough evaluation and investigation. In spine practice, this is very true if we do not feel that the whole spine is considered as one bone, while we realise that spinal pathology might be multiple. So there is nothing to be called, only dorsal, lumbar or cervical MRI; the spine should be screened as one bone.

Again in spine practice, diabetic peripheral neuropathy might be the symptom generator, while the surgeon operates on a false positive MRI finding, thinking that herniated disc is behind the patient suffering.

I met two very surprising stories which are probably unique in spinal practice. In the first story, a 25-year-old lady presented with right lower limb radicular pain. The MRI was suggestive of disc herniation L5-S1 with ill-defined shadow in the same place. After exploration, we found the root was compressed by big central disc from above, and a neural tissue tumour from below.

The second story belongs to an old man who had fracture dislocation of C7-D1 after road traffic accident. He presented with paraparesis. MRI was taken for the cervicodorsal region only. He ended up with fixation which was supposed to improve his condition after surgery. However, he presented with complete paraplegia after three weeks. After screening the whole spine, we discovered an advanced hydatid disease; at level of D7-D8 with spinal cord compression which was behind the deterioration of his condition.

To sum up, life is a school from which we have to learn every day and foolish who learns from his mistakes; he should learn from the mistakes of the others.

We should not forget the painful stories; at the same time, they should form lessons to shape our future.

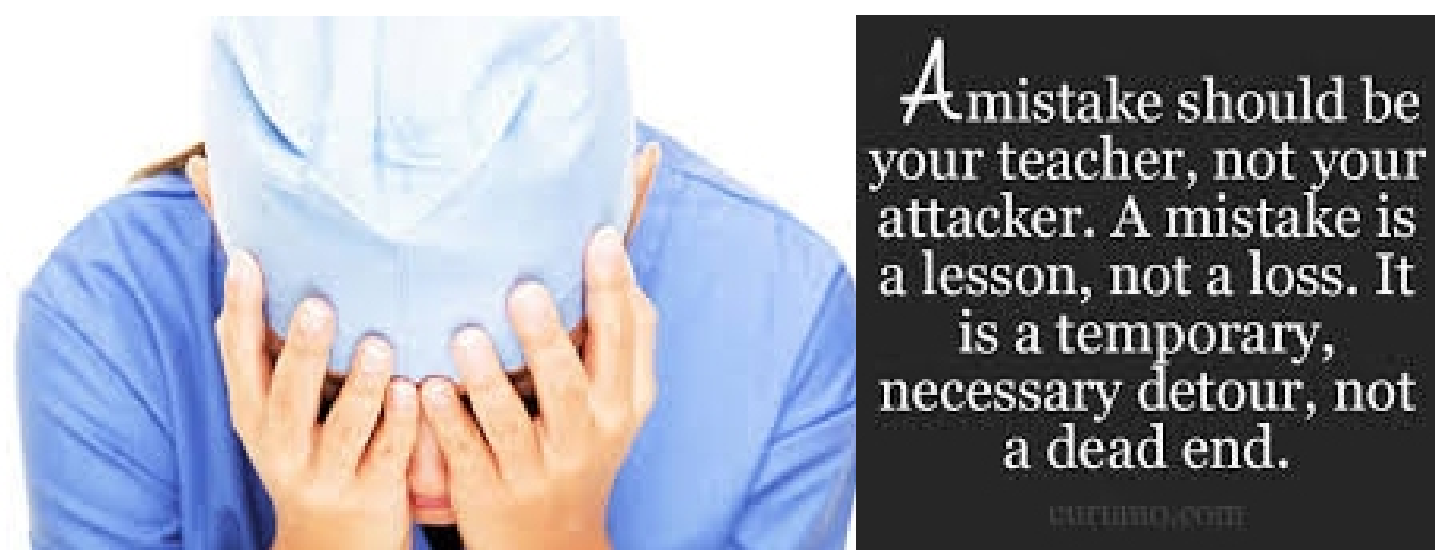

